Article

\title{
Colonization Patterns, Phenology and Seasonal Abundance of the Nearctic Leafhopper Erasmoneura vulnerata (Fitch), a New Pest in European Vineyards
}

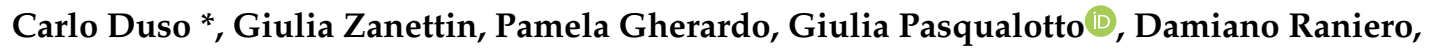 \\ Filippo Rossetto, Paola Tirello and Alberto Pozzebon (D) \\ Department of Agronomy, Food, Natural Resources, Animals and Environment, University of Padova, \\ Viale dell’Università 16, Agripolis, Legnaro, 35020 Padova, Italy; giuliazanettin22@gmail.com (G.Z.); \\ pamela.gherardo@studenti.unipd.it (P.G.); giulia.pasqualotto.2@studenti.unipd.it (G.P.); \\ damiano.raniero@studenti.unipd.it (D.R.); filippo.rossetto.1@studenti.unipd.it (F.R.); paola.tirello@unipd.it (P.T.); \\ alberto.pozzebon@unipd.it (A.P.) \\ * Correspondence: carlo.duso@unipd.it; Tel.: +39-049-8272805
}

Received: 12 August 2020; Accepted: 23 October 2020; Published: 26 October 2020 updates

Simple Summary: The leafhopper Erasmoneura vulnerata (Fitch) (Hemiptera: Cicadellidae) is native to North America, and was found in Europe for the first time (north-eastern Italy) in 2004 where it remained a minor pest of grapevine for more than ten years. Recently, its importance increased in commercial vineyards located in north-eastern Italy, where outbreaks of E. vulnerata populations with severe leaf symptoms were observed despite insecticide applications. Information on its biology and ecology is needed for the development of management strategies. Here, we investigated the phenology and seasonal abundance of E. vulnerata in commercial vineyards. We found that E. vulnerata can complete three generations per growing season. Vineyard colonization by overwintered adults showed a clear edge effect, suggesting an effect of overwintering sites (e.g., rural buildings and hedgerows) adjacent to vineyards. The impact of natural enemies on pest populations appeared to be limited and mostly related to egg parasitoids. Organic vineyards were more heavily infested by E. vulnerata compared to conventional vineyards, likely due to the low effectiveness of natural insecticides typically used in the former farms. The results generated by this study provide implications for the management of this pest in European vineyards.

Abstract: The Nearctic leafhopper Erasmoneura vulnerata (Fitch), detected in Europe for the first time (north-eastern Italy) in 2004, has remained a minor pest of grapevine for more than 10 years. The first outbreaks of E. vulnerata were reported in 2016 in commercial vineyards located in north-eastern Italy. High population densities and severe leaf symptoms (i.e., leaf discoloration and fall) were observed in late summer despite the application of insecticides. Investigations were carried out from 2017 to 2019 in 10 vineyards located in Veneto region (Vicenza and Verona provinces) to shed light on the seasonal abundance of E. vulnerata on different Vitis vinifera cultivars. Pest phenology was studied in six vineyards where the impact of insecticides was minimal. Erasmoneura vulnerata completed three generations in each of the growing seasons. Vineyard colonization by overwintered adults showed a clear edge effect, suggesting the influence of overwintering sites (e.g., rural buildings and hedgerows) in vineyard margins. The impact of natural enemies on pest populations appeared to be limited and mostly related to egg parasitoids. Organic vineyards were more heavily infested by E. vulnerata compared to conventional vineyards, likely due to the minimal efficacy of natural insecticides typically used in the former farms.

Keywords: Erasmoneura vulnerata; Vitis vinifera; edge effect; seasonal abundance; phenology; vineyard management 


\section{Introduction}

The leafhopper Erasmoneura vulnerata (Fitch) (Hemiptera: Cicadellidae) is native to Northern America, and has belonged to the genus Erythroneura for an extended period of time [1-3]. In 2006, Dietrich and Dmitriev [4] placed this species in the genus Erasmoneura, that comprises 11 taxa including Erasmoneura variabilis (Beamer), a key pest in California vineyards [4-8]. In its native range, E. vulnerata was collected on American and European grapevine species, as well as on alternative hosts, primarily Parthenoccissus quinquefolia (L.) Planch, Ilex decidua Walter and Cercis canadensis L. [8]. In some publications, E. vulnerata has been reported as being a severe pest of grapevine in the USA $[9,10]$, but more recent investigations have shown that this species was rarely dominant in leafhopper communities occurring in American vineyards (e.g., [11-13]).

Erasmoneura vulnerata was recorded in Europe for the first time in 2004 (Veneto region, north-eastern Italy) [14]. Some aspects of E. vulnerata behavior in Italy were described by Girolami et al. [15]. Nymphs and adults feed on leaf mesophyll, and feeding sites appear as pale speckled areas. When population densities increase, feeding areas overlap and involve the entire leaf. An additional symptom is represented by the presence of black excrements on the foliage. Heavily infested leaves may dislodge prematurely [12,14]. Information regarding damage assessment and economic thresholds is lacking. Field and semi-field studies carried out on pesticide-free vines suggested that E. vulnerata could develop two or three generations per year $[16,17]$. Pesticide use was likely the most important factor influencing the spread of E. vulnerata into newly invaded areas and its abundance in vineyards. On untreated vines, E. vulnerata dominated over the native leafhoppers Empoasca vitis (Göethe) and Zygina rhamni Ferrari. In contrast, the opposite situation was reported in commercial vineyards where insecticides were applied to control Scaphoideus titanus Ball and other pests [15].

Since 2005, E. vulnerata has spread to new areas both in Italy and Slovenia $[16,18]$, but populations remained at low-density levels in vineyards. This situation changed in 2016, when outbreaks were detected in commercial (Vitis vinifera) vineyards located in the Veneto region (Treviso and Vicenza provinces). In late summer, symptoms caused by this leafhopper were spread on more than $90 \%$ of the canopy, and population densities exceeded 10 nymphs per leaf in some vineyards [19]. Surprisingly, infestations were detected both in conventional and organic vineyards despite the application of insecticides. Recently, E. vulnerata has been recorded in southern Switzerland [20] and Serbia [21].

This new scenario prompted the need for in-depth investigations on colonization patterns, phenology, and abundance in areas where the insect has become a significant pest in vineyards. Previous observations of E. vulnerata phenology were carried out on untreated Vitis labrusca vineyards, and $V$. vinifera cultivars were used for semi-field experiments [17]. These observations also suggest that there may be an effect of overwintering sites at the vineyard borders on the colonization patterns of E. vulnerata like for other leafhoppers [22] Therefore, the phenology of E. vulnerata was studied in some $V$. vinifera vineyards, and the effect of field margins on adult $E$. vulnerata colonization patterns in vineyards was also investigated. Vineyard management (organic vs. conventional) was also considered as a factor influencing the seasonal abundance of E. vulnerata.

\section{Materials and Methods}

\subsection{Study Sites}

Investigations of adult E. vulnerata colonization patterns (i.e., effects of vineyard margins) were carried out in four vineyards per year, from 2017 to 2019 (Table 1). In these vineyards, located in the Vicenza and Verona provinces, the occurrence of E. vulnerata had been reported in the season preceding the study. Vineyards selected for the study on colonization patterns were not treated with insecticides from bud break to blossom when observations were completed. Some of these vineyards were not considered during investigation of $E$. vulnerata phenology because of insecticide applications during the summer; therefore, leafhopper phenology was investigated in two vineyards per year that received limited or no insecticide applications from 2017 to 2019 (Table 1). 
Table 1. Vineyards considered in studies on the colonization patterns and phenology of E. vulnerata. Dots indicate which study was performed in these vineyards.

\begin{tabular}{|c|c|c|c|c|c|c|c|}
\hline Year & Vineyard & Management & Locality & Cultivar & $\begin{array}{l}\text { Insecticides Used } \\
\left(n^{\circ} \text { Applicat. }\right)\end{array}$ & $\begin{array}{l}\text { Colonization } \\
\text { Patterns }\end{array}$ & Phenology \\
\hline 2017 & $\mathrm{AO}$ & Organic & $\begin{array}{c}\text { Alonte } \\
45^{\circ} 22^{\prime} 0^{\prime \prime} \mathrm{N}, 11^{\circ} 25^{\prime} 41^{\prime \prime} \mathrm{E}\end{array}$ & $\begin{array}{c}\text { Merlot, Glera, } \\
\text { Pinot gris, Incrocio } \\
\text { Manzoni } 6013\end{array}$ & Pyrethrins (1) & - & - \\
\hline 2017 & LO1 & Organic & $\begin{array}{c}\text { Lonigo } \\
45^{\circ} 23^{\prime} 18^{\prime \prime} \mathrm{N}, 11^{\circ} 23^{\prime} 24^{\prime \prime} \mathrm{E}\end{array}$ & Merlot, Trebbiano T. & Insecticide-free & $\bullet$ & \\
\hline 2017 & $\mathrm{AC}$ & Conventional & $\begin{array}{c}\text { Alonte } \\
45^{\circ} 21^{\prime} 33.6^{\prime \prime} \mathrm{N}, 11^{\circ} 26^{\prime} 11.3^{\prime \prime} \mathrm{E} \\
\text { Lonigo }\end{array}$ & $\begin{array}{c}\text { Cabernet S., Pinot gris, } \\
\text { Glera } \\
\text { Garganega, }\end{array}$ & Insecticide-free & $\bullet$ & - \\
\hline 2017 & $\mathrm{LC}$ & Conventional & $45^{\circ} 24^{\prime} 16.2^{\prime \prime} \mathrm{N} 11^{\circ} 22^{\prime} 32.2^{\prime \prime} \mathrm{E}$ & $\begin{array}{c}\text { Chardonnay, } \\
\text { Merlot }\end{array}$ & Insecticide-free & $\bullet$ & \\
\hline 2018 & $\mathrm{AO}$ & Organic & $\begin{array}{c}\text { Alonte } \\
45^{\circ} 22^{\prime} 38.6^{\prime \prime} \mathrm{N} 11^{\circ} 24^{\prime} 30.6^{\prime \prime} \mathrm{E}\end{array}$ & Merlot, Glera & Insecticide-free & $\bullet$ & \\
\hline 2018 & LO2 & Organic & $\begin{array}{c}\text { Lonigo } \\
45^{\circ} 22^{\prime} 41.2^{\prime \prime} \mathrm{N} 11^{\circ} 24^{\prime} 34.4^{\prime \prime} \mathrm{E}\end{array}$ & Trebbiano T., Cabernet S. & Insecticide-free & • & $\bullet$ \\
\hline 2018 & $\mathrm{MO}$ & Organic & $\begin{array}{c}\text { Monteforte } \\
45^{\circ} 25^{\prime} 5^{\prime \prime} \mathrm{N}, 11^{\circ} 17^{\prime} 4^{\prime \prime} \mathrm{E}\end{array}$ & Garganega & Mineral oil (1) & & $\bullet$ \\
\hline 2018 & $\mathrm{LC}$ & Conventional & Lonigo & Garganega & Insecticide-free & $\bullet$ & \\
\hline 2018 & MC & Conventional & $\begin{array}{c}\text { Monteforte } \\
45^{\circ} 27^{\prime} 16.6^{\prime \prime} \mathrm{N}, 11^{\circ} 16^{\prime} 59.2^{\prime \prime} \mathrm{E}\end{array}$ & Trebbiano S. & Insecticide-free & $\bullet$ & \\
\hline 2019 & LO1 & Organic & Lonigo & Merlot & Pyrethrins (2) & - & - \\
\hline 2019 & MO & Organic & Monteforte & Garganega & Insecticide-free & - & - \\
\hline 2019 & AC & Conventional & Alonte & Cabernet S., Glera & Insecticide-free & • & \\
\hline 2019 & GC & Conventional & $\begin{array}{c}\text { Gambellara } \\
45^{\circ} 24^{\prime} 17.9^{\prime \prime} \mathrm{N} 11^{\circ} 22^{\prime} 31.8^{\prime \prime} \mathrm{E}\end{array}$ & Garganega & Insecticide-free & $\bullet$ & \\
\hline
\end{tabular}




\subsection{Effects of Distance from Vineyard Margins on Erasmoneura vulnerata Colonization Patterns}

Observations carried out before bud break revealed the occurrence of many E. vulnerata adults on hedges and shrubs (e.g., associated with rural buildings, suggesting that leafhoppers overwintered at these sites). In particular, we observed E. vulnerata adults on Parthenocyssus tricuspidata, Rosa spp. and Prunus spp. The presence of hedgerows contiguous to vineyards was also considered to be a factor potentially affecting E. vulnerata overwintering [13], and thus the role of vineyard margins in the leafhopper's colonization was investigated. In 2017, four transects, each comprising four yellow sticky traps, were arranged at increasing distances from rural buildings and hedgerows contiguous to AC vineyard. Four positions were identified for trap placement: A (first vineyard row close to rural buildings or hedgerows), B, C, and D (20,40, and $60 \mathrm{~m}$ from position A, respectively) (Figure 1). An additional five transects were arranged in $\mathrm{AO}$ and $\mathrm{LO} 1 \mathrm{farms}$ for a total of nine transects in the 2017 growing season. Observations were carried out from April to June, focusing on the most common leafhopper species, i.e., E. vulnerata, E. vitis and Z. rhamni; they were identified using keys published by Dmitriev [8] and Vidano [23]. Traps were analyzed in the laboratory using a stereomicroscope and were replaced every 7-10 days. In 2018 and 2019, a total of four transects (one per vineyard) were planned. Sampling was carried out from April to June, adopting the experimental approach from 2017.

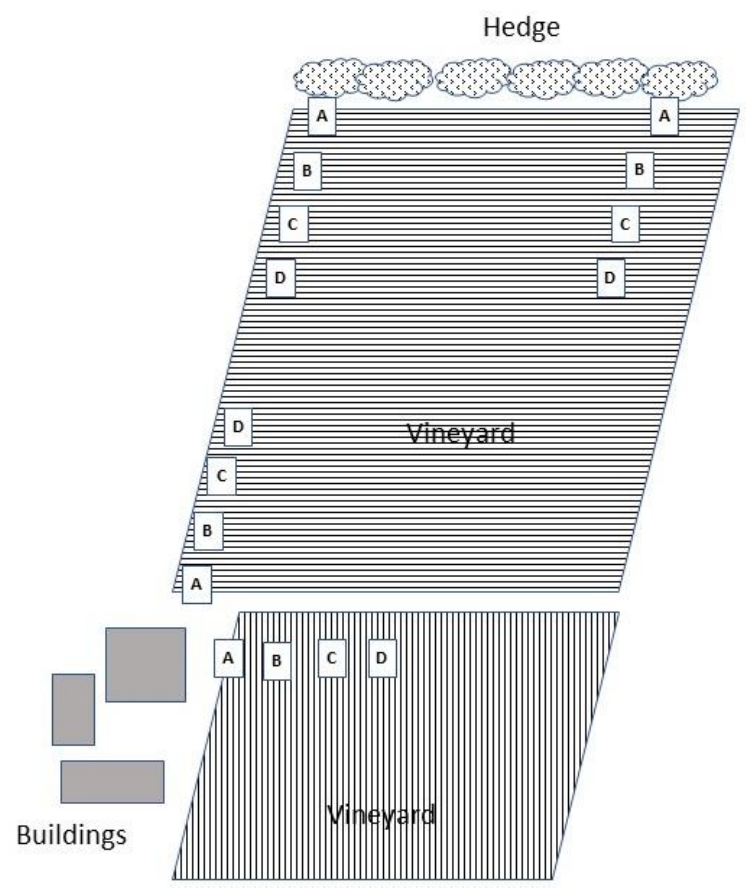

Figure 1. Example of trap position in the study on the effects of distance from vineyard margins on E. vulnerata colonization patterns (AC vineyard in 2017).

\subsection{Phenology of Erasmoneura vulnerata}

In 2017, leaf sampling was regularly carried out on insecticide-free plots of AC vineyard (cv. Cabernet Sauvignon), while in AO vineyard (cvs. Merlot, Glera, Pinot gris, Incrocio Manzoni 6013) pyrethrins were only applied in late July to control S. titanus. In AC vineyard, a total of 30 leaves were inspected every 7-10 days in the laboratory using a dissecting microscope. Individual leafhoppers were counted considering their identity and age, and age was subdivided into three categories (I-II instar nymphs, III-V instar nymphs, adults). The occurrence of potential predators or parasites of leafhoppers on leaf samples was also evaluated, as well as egg parasitoid emergence holes. Data from leaf samplings were coupled with data from adults captured on four yellow sticky traps placed within the grapevine canopy. Traps were analyzed in the laboratory under a dissecting microscope and were renewed every sampling date. The same procedure was applied in AO vineyard, where a total of 60 leaves 
(15 leaves per cultivar) were analyzed. In 2018, 30 leaves were collected in LO2 and MO vineyards approximately every 10-15 days and were then analyzed in the laboratory following the previously described procedures. Four yellow sticky traps were also placed in each vineyard. Mineral oils were applied in MO vineyard. The same approach was applied in 2019 in LO1 and MO vineyards. Pyrethrins were applied in LO1 vineyard, and kaolin in MO vineyard.

\subsection{Effects of Vineyard Management on Erasmoneura vulnerata Seasonal Abundance}

In 2018, the effect of vineyard management (organic vs. conventional) on E. vulnerata abundance was tested comparing four organic and four conventional vineyards located in the Vicenza and Verona provinces (at Alonte, Lonigo, Monteforte d'Alpone, Roncà). We selected AO, LO2, MO, and MO2 among organic vineyards (MO2 vineyard was located at Monteforte D'Alpone and comprised Garganega cultivar), while AC, LC, MC, and RC were selected among conventional vineyards (RC vineyard was located at Roncà and comprised Garganega cultivar). In each vineyard, 30 leaves and four yellow sticky traps were analyzed in the laboratory approximately every two weeks, from May to September. Leafhoppers were identified at species level focusing on E. vulnerata, E. vitis, and Z. rhamni. The number of egg parasitoid (Hymenoptera: Mymaridae) emergence holes was also taken into account to calculate parasitism rates. These values were calculated by dividing the number of parasitoid emergence holes by the sum of the nymph hatching holes and the parasitoid emergence holes, expressed as a percentage. A number of emerging cages [20] were used to isolate adult parasitoids and identify them to the species level using molecular markers. Using the salting-out protocol [24], mitochondrial DNA was extracted from 15 samples of the parasitoid Anagrus spp., which were reared in the laboratory from grapevine leaves infested by E. vulnerata. A fragment of the cytochrome c oxidase subunit 1 (COI) was amplified and sequenced using the procedure described in Martinez-Sañudo et al. [25].

\subsection{Statistical Analyses}

Data from these experiments aimed at investigating the effects of distance from vineyard margins on leafhopper colonization and were analyzed using repeated measures linear mixed model with the MIXED procedure of SAS ${ }^{\circledR}$ (ver. 9.3; SAS Institute Inc., Cary, NC, USA). Distance from the margin, time of sampling, and their interaction were considered as sources of variation in the model and were tested using an F test $(\alpha=0.05)$. The transect was considered as a random effect in the model. Pairwise comparisons of catches placed at different distances were performed using Tukey's test $(\alpha=0.05)$ on the least-square means. The degrees of freedom were estimated with Kenward-Roger method. Prior to the analysis, data were checked for model assumptions. The model was run on data transformed to $\log (n+1)$, while untransformed data are shown in figures.

Effects of vineyard management on the abundance of E. vulnerata, E. vitis and Z. rhamni adults on traps, nymphs on leaves, as well as on the parasitism rate by the Mymaridae were analyzed separately with a repeated measures linear mixed model with the MIXED procedure of SAS ${ }^{\circledR}$ (ver. 9.3; SAS Institute Inc., Cary, NC, USA). In this analysis, vineyard management (organic vs. conventional), time of sampling, and their interaction were considered as sources of variation and were tested with an $\mathrm{F}$ test $(\alpha=0.05)$. Comparisons between vineyard management on each date were performed using Tukey's test $(\alpha=0.05)$ on the least-square means. The degrees of freedom were estimated using the Kenward-Roger method. Prior to the analysis, data were checked for model assumptions, and leafhoppers captures were transformed to $\log (n+1)$, while arcsin of the square root was applied to the parasitism rate data. Untransformed data are shown in the figures. 


\section{Results}

\subsection{Effects of Distance from Vineyard Margins on Erasmoneura vulnerata Colonization Patterns}

\subsubsection{7}

Adult E. vulnerata catches were abundant in late April when adults moved inside the vineyards, while catch numbers declined in May and slightly increased in June ( $\mathrm{F}=24.15$; d.f. $=7,179 ; p<0.0001$; Figure 2). Differences among treatments (increasing distances from the margin) were significant $(\mathrm{F}=4.11$; d.f. $=3,30.6 ; p=0.014)$ and the most abundant catch numbers were detected at the vineyard margin (0 m vs. $40 \mathrm{~m}: \mathrm{t}=3.01$; d.f. $=30.6 ; p=0.025 ; 0 \mathrm{~m}$ vs. $60 \mathrm{~m}: \mathrm{t}=2.94 ; \mathrm{d} . \mathrm{f} .=30.7 ; p=0.029)$. There were no differences between catches on traps located at $0 \mathrm{~m}$ and $20 \mathrm{~m}(\mathrm{t}=1.41 ; \mathrm{d} . \mathrm{f} .=30.6$; $p=0.506)$. The remaining comparisons were not significant $(20 \mathrm{~m}$ vs. $40 \mathrm{~m}: \mathrm{t}=1.6$; d.f. $=30.5 ; p=0.392$; $20 \mathrm{~m}$ vs. $60 \mathrm{~m}: \mathrm{t}=1.54$; d.f. $=30.6 ; p=0.426 ; 40 \mathrm{~m}$ vs. $60 \mathrm{~m}: \mathrm{t}=-0.06$; d.f. $=30.6 ; p=0.999)$. Empoasca vitis and Zygina rhamni catch numbers were much lower, and reached the highest levels in June (Figure 2). The effect of margins on number of adult catches was not significant $(F=1.56 ;$ d.f. $=3,60$; $p=0.208 ; \mathrm{F}=0.55 ;$ d.f. $=3,53.2 ; p=0.653$ for E. vitis and Z. rhamni, respectively).

\section{Erasmoneura vulnerata}

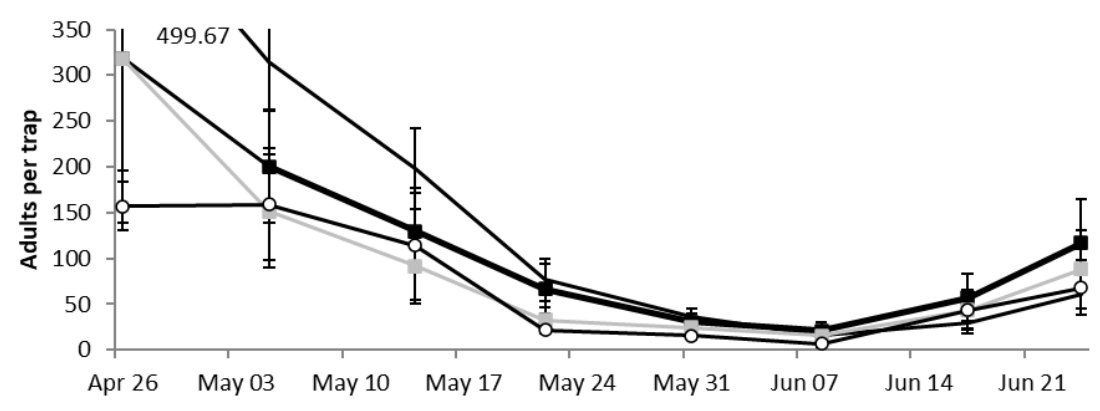

Empoasca vitis

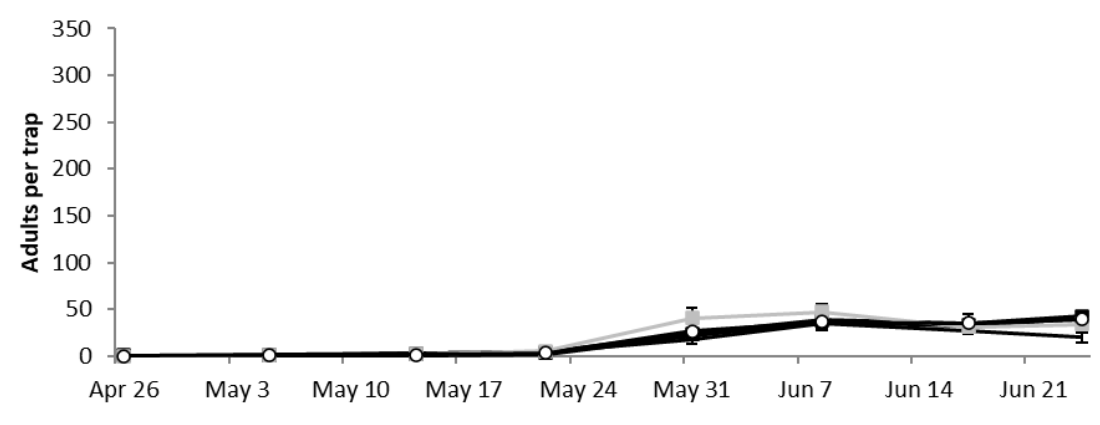

Zygina rhamni

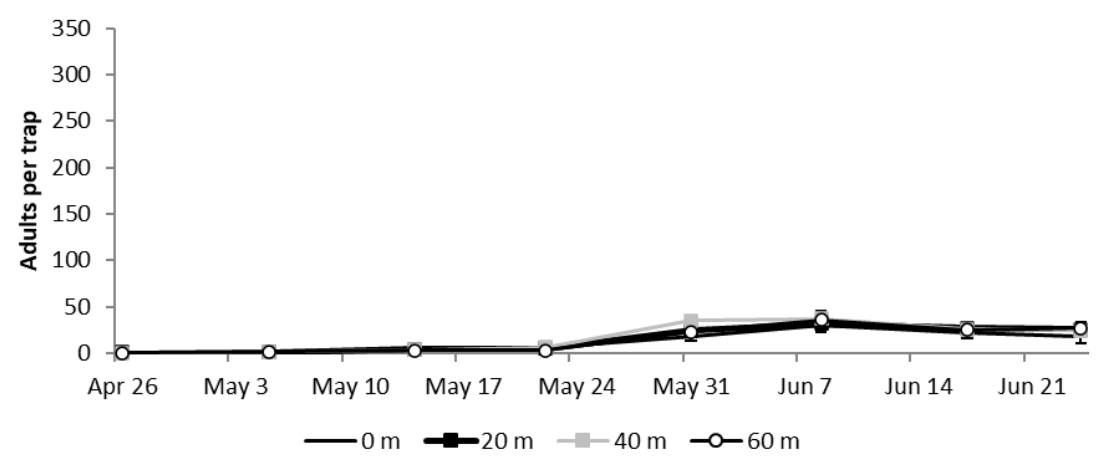

Figure 2. Mean ( \pm std. err.) number of adult E. vulnerata, E. vitis and Z. rhamni catches on traps placed at increasing distances from the vineyard margins in the spring of 2017. 


\subsubsection{8}

Numbers of adult E. vulnerata catches were higher than those of E. vitis and Z. rhamni in early spring of 2018 (Figure 3). Adult E. vulnerata numbers fluctuated over the sampling dates leading to a significant effect of time ( $\mathrm{F}=9.01 ;$ d.f. $=4,40.4 ; p<0.0001)$. Differences among treatments (increasing distances from the margin) were also significant ( $\mathrm{F}=7.45$; d.f. $=3,9.88 ; p=0.0068)$ and the number of catches was higher at the vineyard margin $(0 \mathrm{~m}$ vs. $20 \mathrm{~m}: \mathrm{t}=3.56$; d.f. $=9.88 ; p=0.023 ; 0 \mathrm{~m}$ vs. $40 \mathrm{~m}: \mathrm{t}=3.82$; d.f. $=9.88 ; p=0.015 ; 0 \mathrm{~m}$ vs. $60 \mathrm{~m}: \mathrm{t}=4.12$; d.f. $=9.88 ; p=0.009$ ). The remaining comparisons were not significant $(20 \mathrm{~m}$ vs. $40 \mathrm{~m}: \mathrm{t}=0.26$; d.f. $=9.88 ; p=0.994 ; 20 \mathrm{~m}$ vs. $60 \mathrm{~m}: \mathrm{t}=0.56$; d.f. $=9.88 ; p=0.994 ; 40 \mathrm{~m}$ vs. $60 \mathrm{~m}: \mathrm{t}=0.31$; d.f. $=9.88 ; p=0.989$ ). The number of $Z$. rhamni and $E$. vitis catches reached the highest levels in June (Figure 2), and the effect of margins on their adults was not significant $(\mathrm{F}=0.87 ;$ d.f. $=3,15.8 ; p=0.477 ; \mathrm{F}=1.56 ;$ d.f. $=3,16.2 ; p=0.236)$.

\section{Erasmoneura vulnerata}

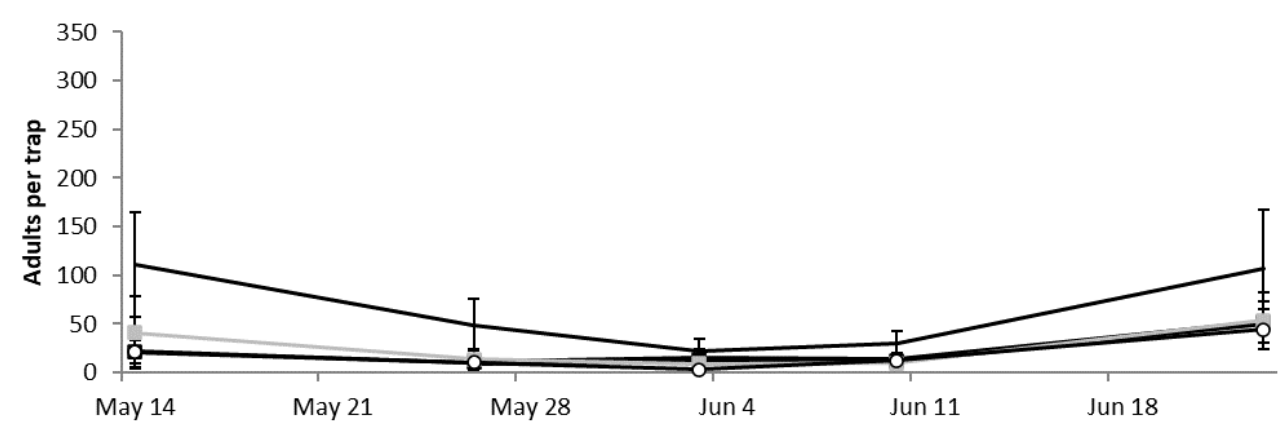

Empoasca vitis

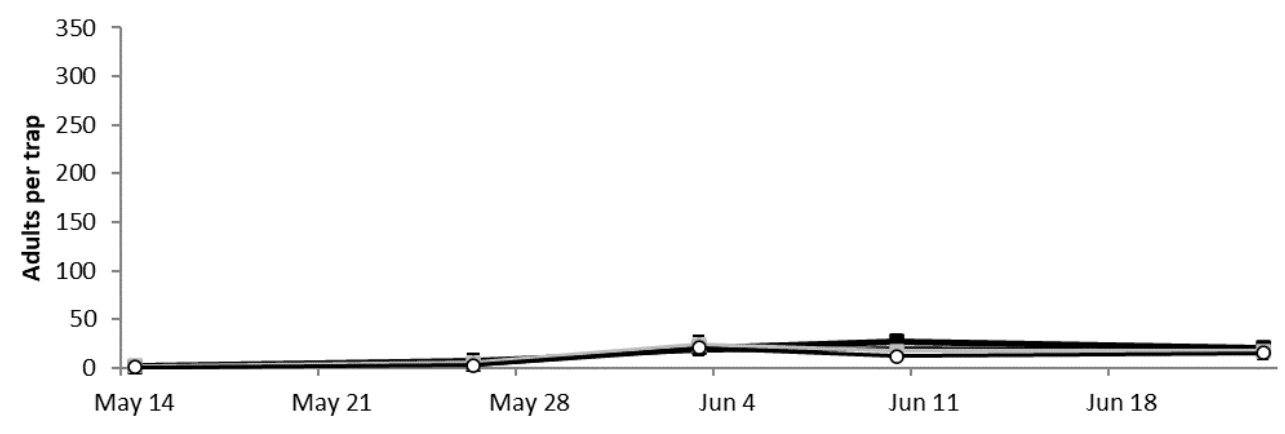

Zygina rhamni

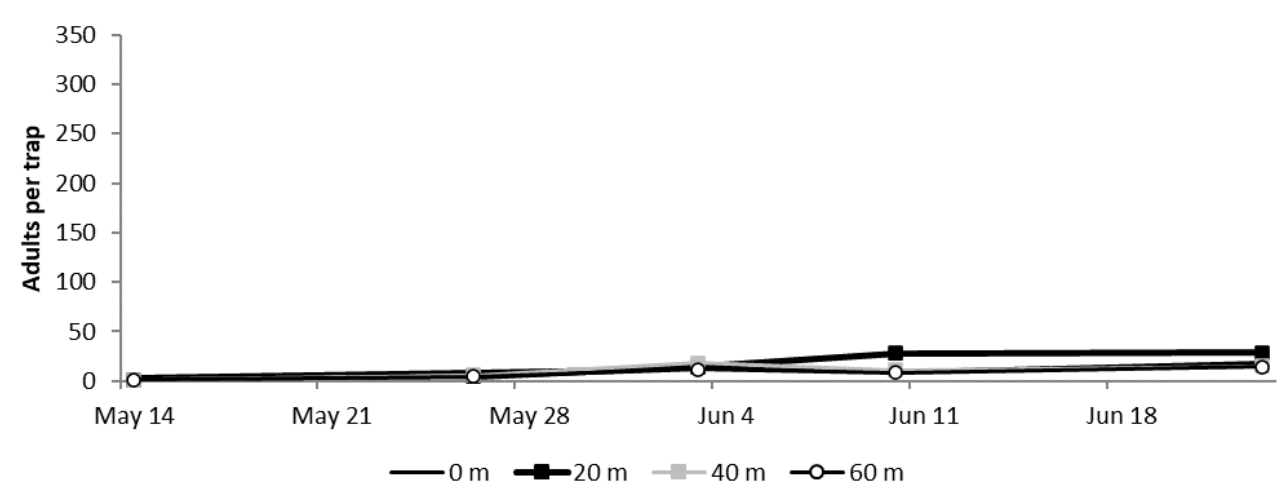

Figure 3. Mean ( \pm std. err.) number of adult E. vulnerata, E. vitis and Z. rhamni catches on traps placed at increasing distances from the vineyard margins in the spring of 2018. 


\subsubsection{9}

The number of E. vulnerata catches increased in April when adults moved inside the vineyards, while later catches declined in number $(\mathrm{F}=11.99 ;$ d.f. $=6,78.3 ; p<0.0001$; Figure 4$)$. Differences among treatments were significant $(\mathrm{F}=5.19 ; \mathrm{d} . \mathrm{f} .=3,21.6 ; p=0.044)$, and the highest number of catches were detected at the vineyard margin ( $0 \mathrm{~m}$ vs. $20 \mathrm{~m}: \mathrm{t}=2.12 ; \mathrm{d} . \mathrm{f} .=21.6 ; p=0.045 ; 0 \mathrm{~m}$ vs. $40 \mathrm{~m}: \mathrm{t}=2.71$; d.f. $=21.6 ; p=0.013 ; 0 \mathrm{~m}$ vs. $60 \mathrm{~m}: \mathrm{t}=2.59 ;$ d.f. $=21.6 ; p=0.017)$. The remaining comparisons were not significant $(20 \mathrm{~m}$ vs. $40 \mathrm{~m}: \mathrm{t}=0.59 ;$ d.f. $=21.6 ; p=0.564 ; 20 \mathrm{~m}$ vs. $60 \mathrm{~m}: \mathrm{t}=0.46 ;$ d.f. $=21.6 ; p=0.648$; $40 \mathrm{~m}$ vs. $60 \mathrm{~m}: \mathrm{t}=-0.12$; d.f. $=21.6 ; p=0.903)$. The number of E. vitis and Z. rhamni catches were much lower (Figure 3), and the effect of margins on them was not significant $(\mathrm{F}=0.19$; d.f. $=3,23.2 ; p=0.9$; $\mathrm{F}=0.1$; d.f. $=3,99.7 ; p=0.961$ for E. vitis and Z. rhamni, respectively).

\section{Erasmoneura vulnerata}

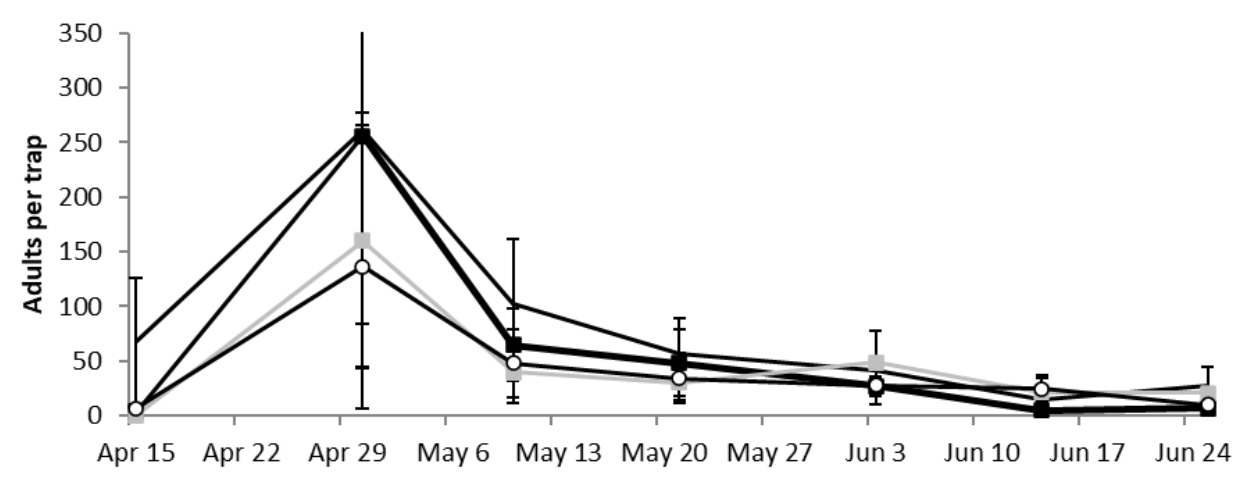

Empoasca vitis

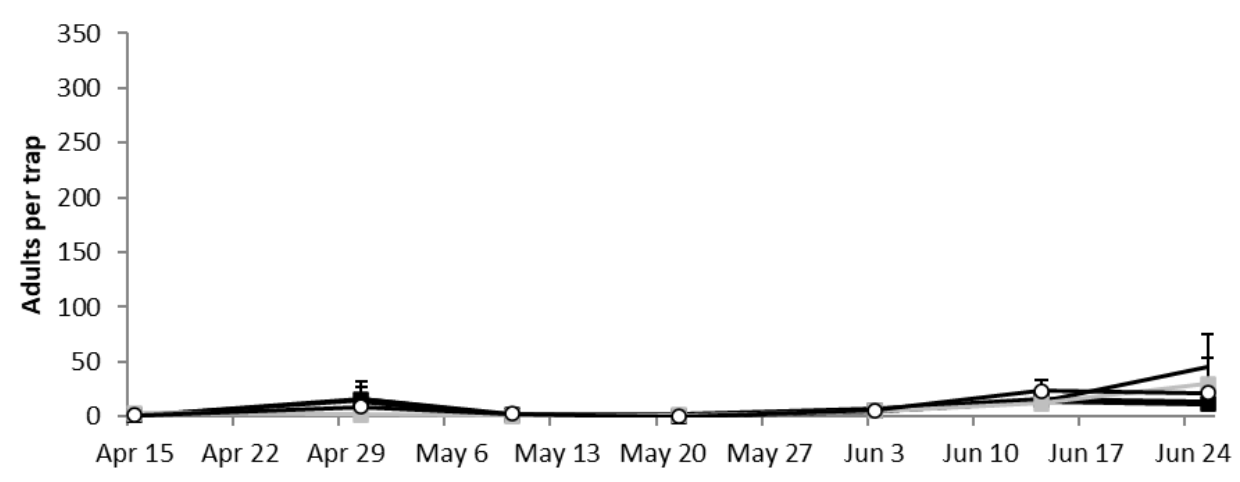

Zygina rhamni

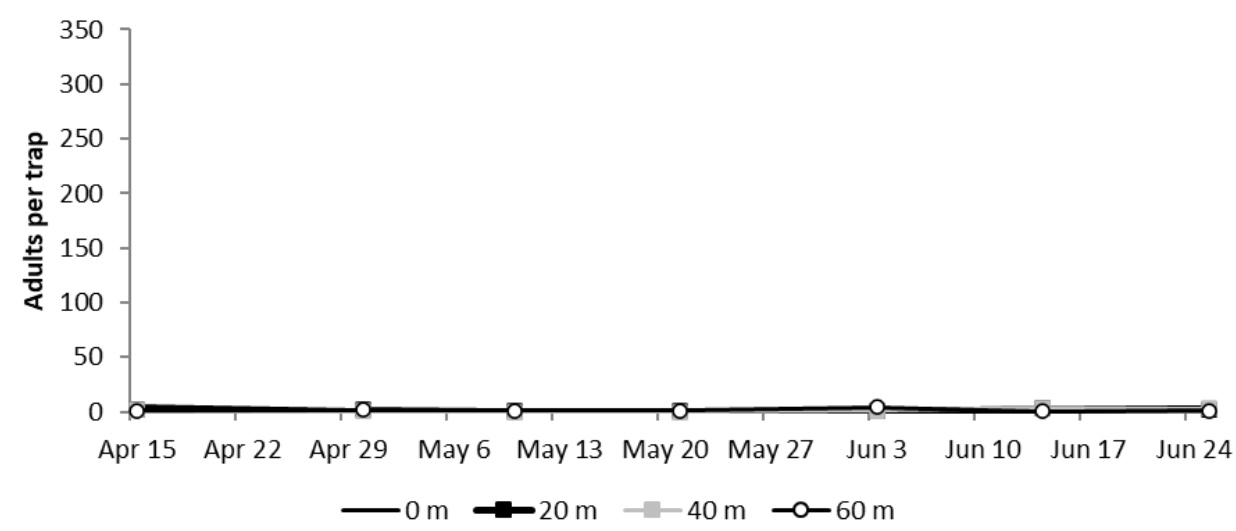

Figure 4. Mean ( \pm std. err.) number of adult E. vulnerata, E. vitis and Z. rhamni catches on traps placed at increasing distances from the vineyard margins in the spring of 2019. 


\subsection{Phenology of Erasmoneura vulnerata}

\subsubsection{7}

At bud break in 2017 (April 10th), high numbers of E. vulnerata adults were caught on yellow sticky traps of the selected vineyards (Figure 5). The number of E. vitis and Z. rhamni catches was much lower (data not shown). In subsequent weeks, the number of E. vulnerata catches declined. In AC vineyard, early instar nymphs of E. vulnerata were first detected in the second half of May, and their densities peaked in late May (Figure 5). Older nymph numbers peaked in early June. The abundance of early instar nymphs showed two additional peaks in early July and late August, followed by those of older nymphs. The number of adult catches showed two clear peaks following those of older nymphs in early July and early August. Their numbers declined in late summer. The data strongly suggest the development of three generations. Densities of other leafhopper taxa in leaf samples were negligible (data not shown).

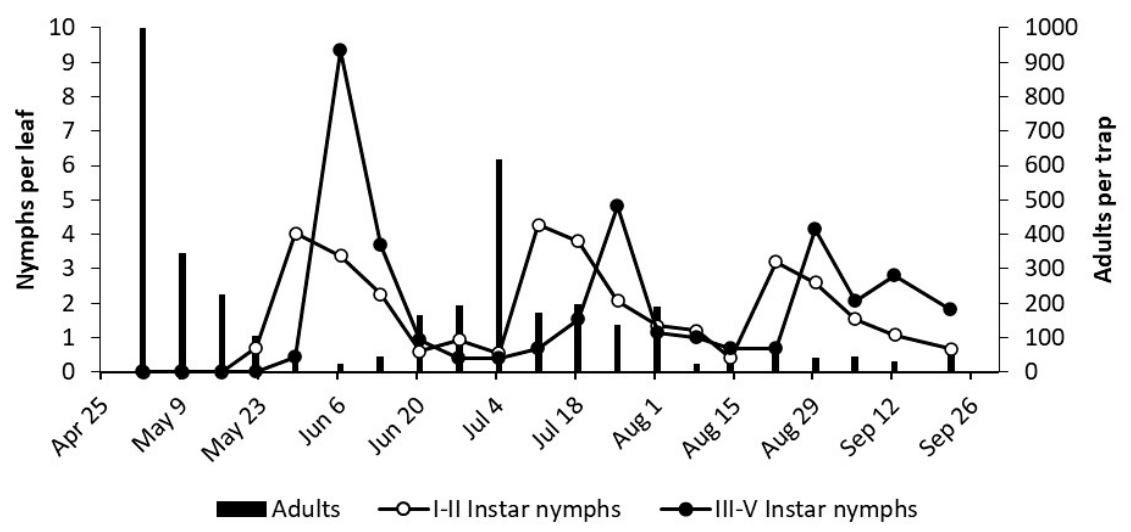

Figure 5. The phenology of E. vulnerata in AC vineyard in the growing season of 2017.

In $\mathrm{AO}$ vineyard, observations were carried out on four different varieties, and the phenology of E. vulnerata reported in Figure 6 was obtained by combining these data. Early instar nymphs were detected from late May, and their densities peaked in early June, followed by an increase in older nymphs and adults; therefore, the first generation developed in a similar way to that of the AC vineyard. A new increase in early instar nymphs in the first half of July was compatible with the start of the second generation; however, in contrast with the situation reported in AC vineyard, older nymphs reached negligible densities in July. This was likely due to the application of pyrethrins to control S. titanus. A slight increase in early instar nymphs detected in late August and early September could indicate the onset of the third generation. The occurrence of other leafhoppers in this vineyard was negligible (data not shown).

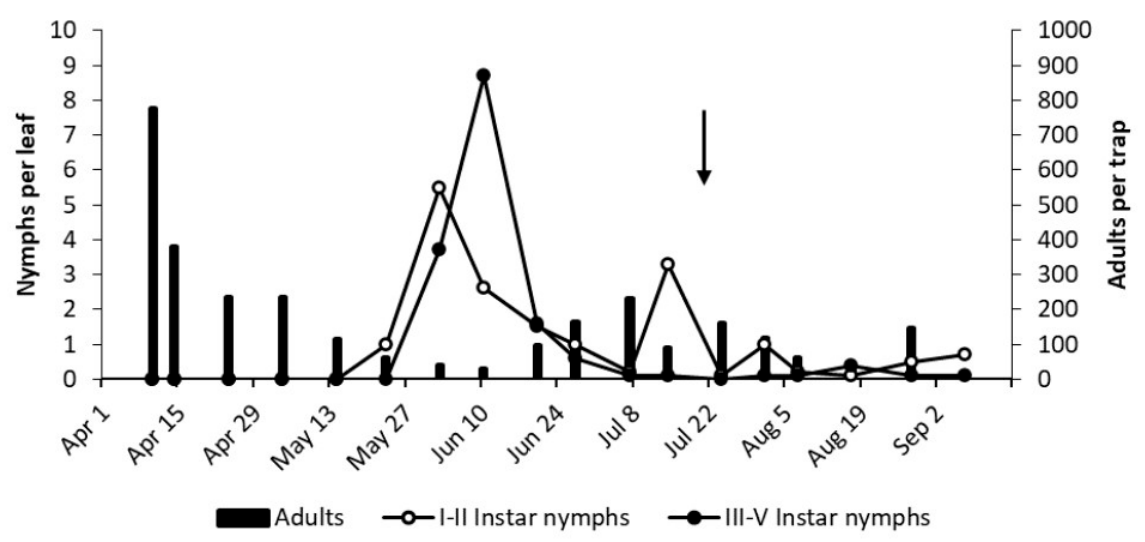

Figure 6. The phenology of E. vulnerata in AO vineyard in the growing season of 2017. Arrow indicates pyrethrins treatment. 


\subsubsection{8}

At bud break in 2018, E. vulnerata adults were abundant; however, when regular sampling started in early May, the number of adult catches in the selected vineyards (MO and LO2) were relatively low (Figures 7 and 8). Early instar nymphs were first detected in mid-May, and their numbers peaked in late May, followed by peaks of older nymphs (Figures 7 and 8). The dynamics of early instar nymphs showed additional peaks in the second half of July and in late August to early September, whereas older nymphs peaked in the same or in subsequent sampling dates. Adult numbers (caught on traps) did not follow homogenous patterns, but, in most cases, reached higher numbers in August (Figures 7 and 8). The occurrence of other leafhoppers on traps, as well on leaf samples, was much lower (data not shown).

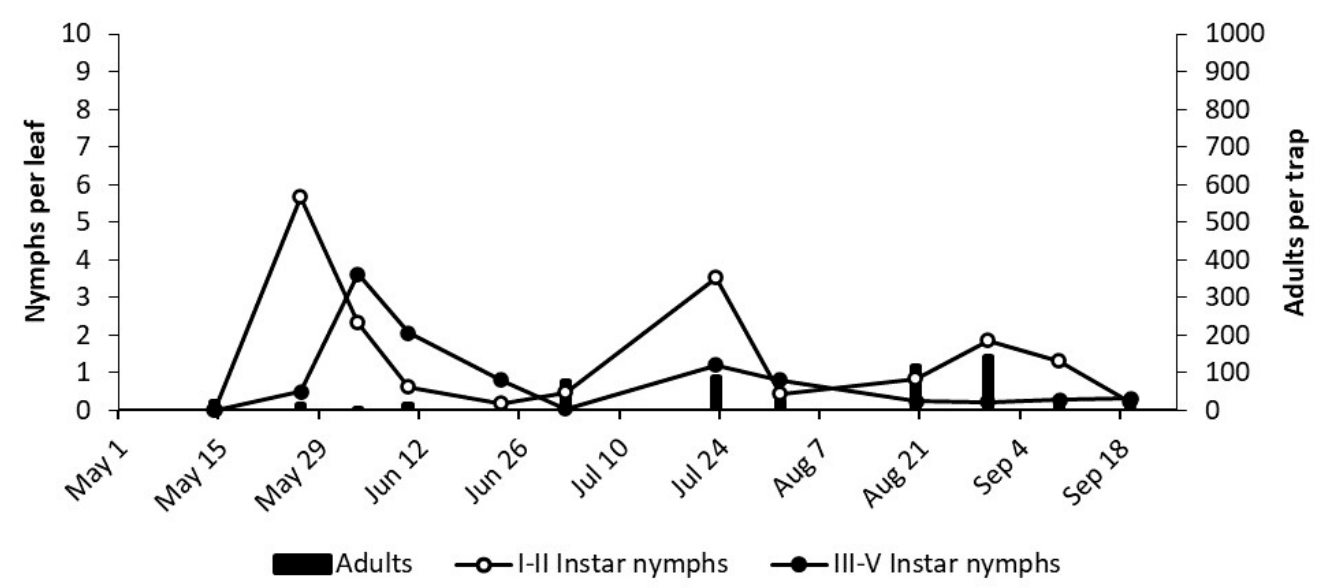

Figure 7. The phenology of .E. vulnerata in MO vineyard in the growing season of 2018.

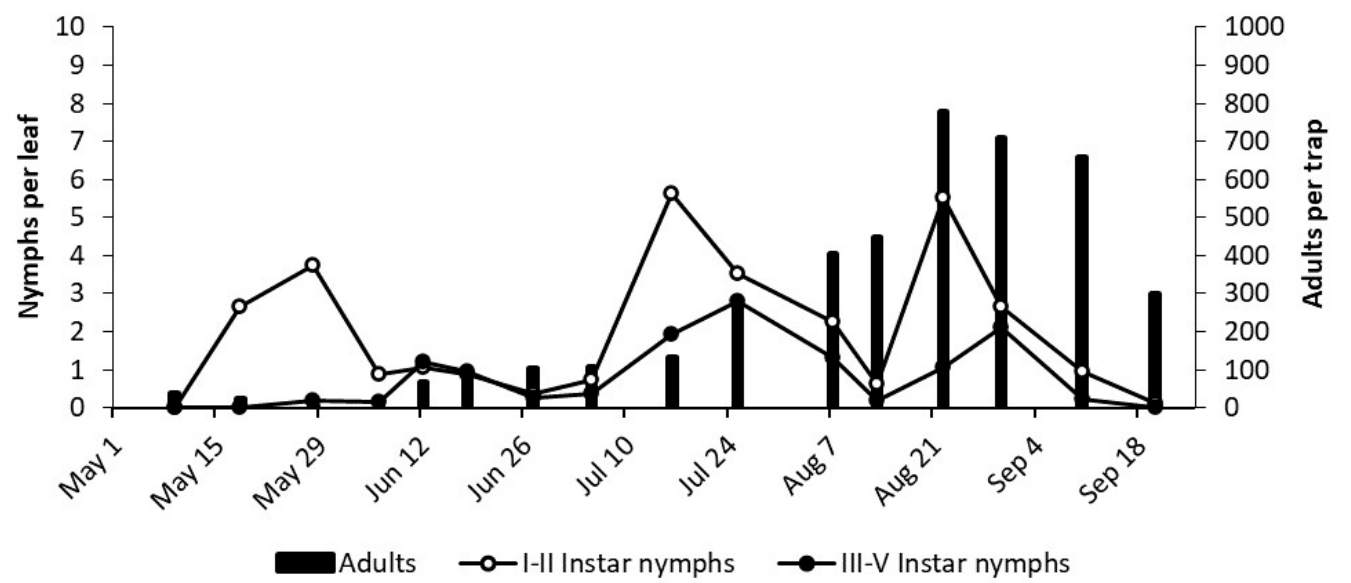

Figure 8. The phenology of E. vulnerata in LO2 vineyard in the growing season of 2018.

3.2.3. 2019

The number of adult E. vulnerata catches was low in the spring of 2019, likely due to the occurrence of frequent rainfall (Figures 9 and 10). Early instar nymphs peaked in mid-June, late July, and the first half of September in both vineyards (Figures 9 and 10). Excluding late summer, the dynamics of older nymphs and adults were consistent with that of early nymphs (Figures 9 and 10). Low densities of E. vitis and Z. rhamni were recorded in both vineyards. 


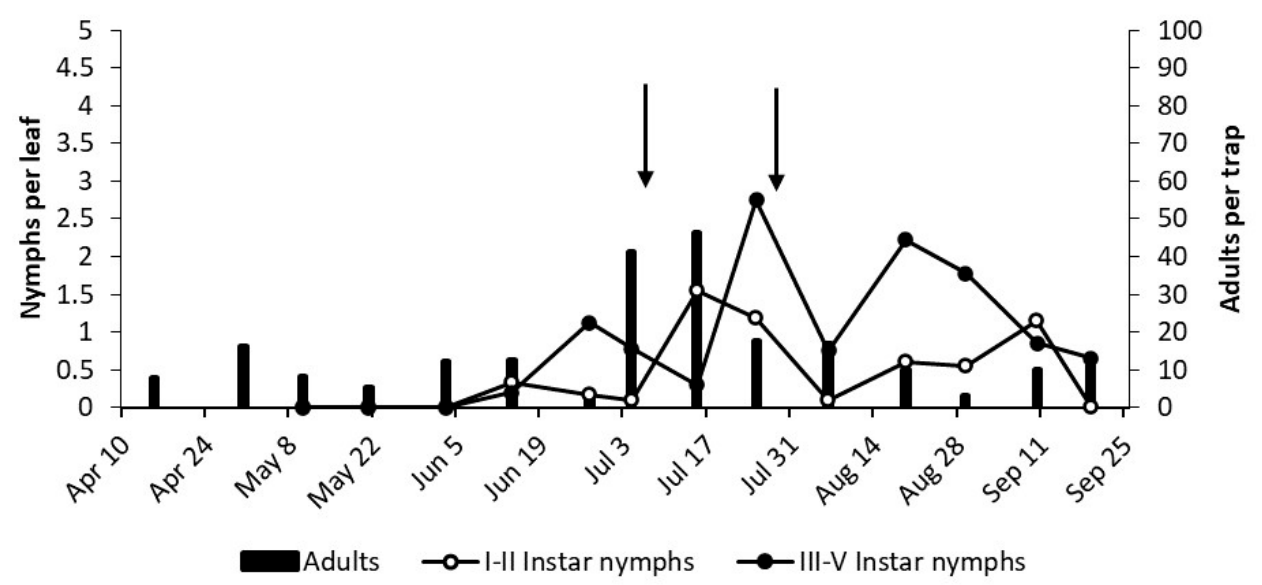

Figure 9. The phenology of E. vulnerata in LO1 vineyard in the growing season of 2019. Arrows indicate pyrethrins treatments.

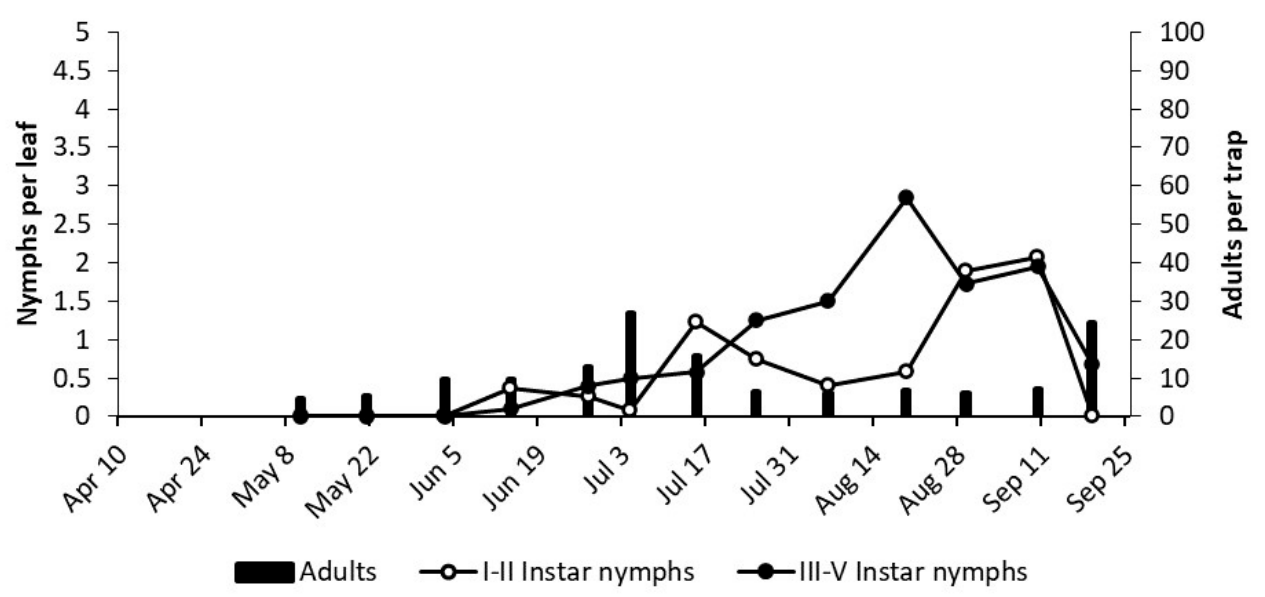

Figure 10. The phenology of E. vulnerata in MO vineyard in the growing season of 2019.

\subsection{Natural Control}

A number of Heteroptera (Malacocoris chlorizans Panzer and Orius spp. in particular), as well as Neuroptera (e.g., Chrysoperla carnea Stephens), were seldom observed preying on leafhopper nymphs in leaf samples. Nymphs of Allothrombium sp. (Acari Prostigmata) were also detected feeding on leafhopper nymphs. Parasitism by Hymenoptera Mymaridae was ascertained in all vineyards through the observation of emergence holes left by parasitoid adults on leaf veins. Among the Mymaridae that emerged from grapevine leaves in the laboratory, 14 individuals belonged to Anagrus parvus Soyka sensu Viggiani [26] and only one belonged to Anagrus atomus (Linnaeus) [27].

\subsection{Effect of Vineyard Management}

The number of adult E. vulnerata catches was higher in organic vineyards ( $\mathrm{F}=6.05$; d.f. $=1,37.5$; $p=0.018)$ and differed by the time of sampling and by the interaction vineyard management * time $(\mathrm{F}=17.00 ;$ d.f. $=11,308 ; p<0.0001 ; \mathrm{F}=2.56 ;$ d.f. $=11,318 ; p=0.004$, respectively $)$. The number of adult E. vulnerata catches was higher in organic vineyards on multiple sampling dates (Figure 10). Vineyard management affected the number of adult $E$. vitis catches $(\mathrm{F}=27.11 ; \mathrm{d} . \mathrm{f} .=1,61.08 ; p<0.0001)$ as well as the effect of time and the interaction vineyard management $*$ time $(\mathrm{F}=19.33$; d.f. $=11,313$; $p<0.0001 ; \mathrm{F}=3.47$; d.f. $=11,313 ; p=0.001)$. In particular, the number of $E$. vitis catches was higher in conventional than in organic vineyards on multiple dates (Figure 10). Similar trends emerged for Z. rhamni (vineyard management: $\mathrm{F}=6.05$; d.f. $=1$, 37.5; $p=0.018$; time: $\mathrm{F}=17.00$; d.f. $=11,318$; 
$p<0.0001$; vineyard management $*$ time: $\mathrm{F}=2.56$; d.f. $=11,318 ; p=0.004$; respectively). On some dates, there were more Z. rhamni adults in conventional vineyards (Figure 11).

\section{Erasmoneura vulnerata}

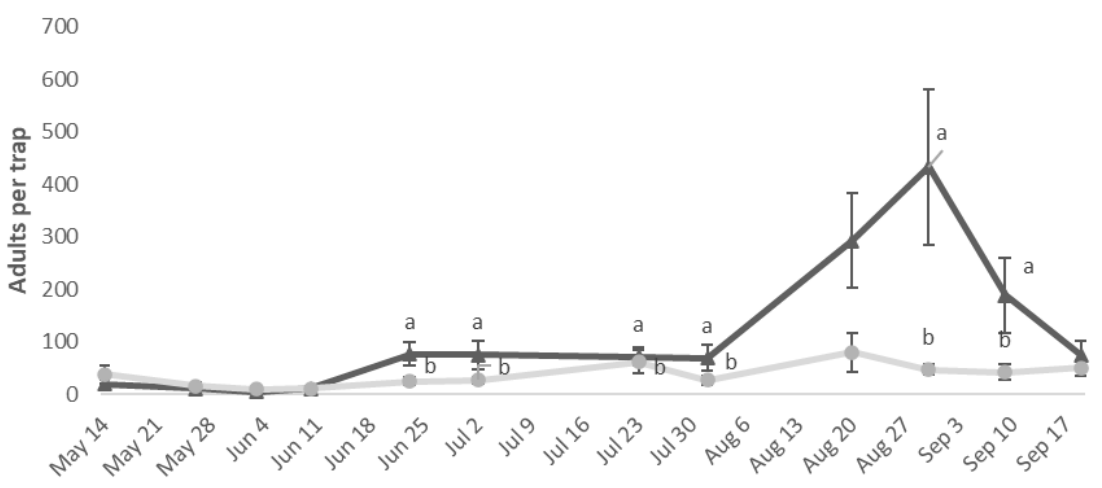

Empoasca vitis

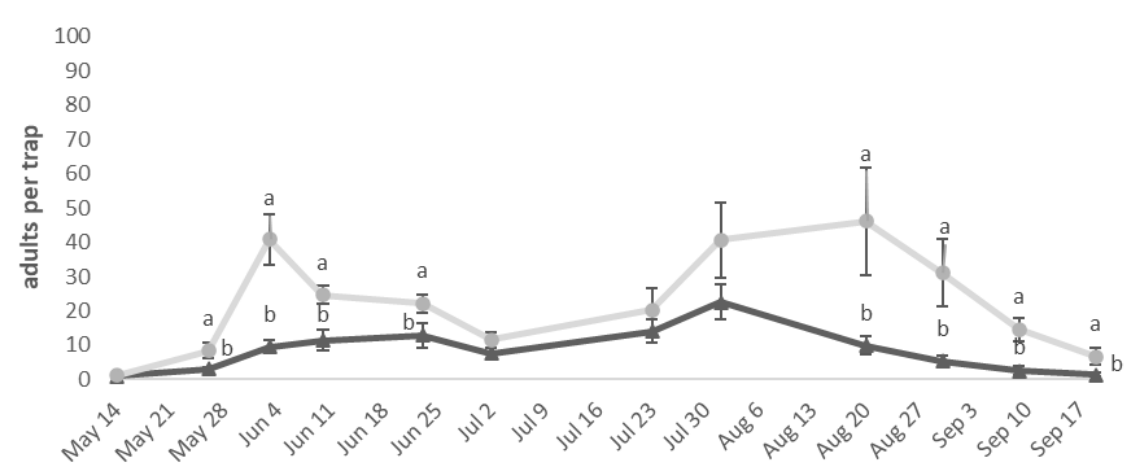

Zygina rhamni

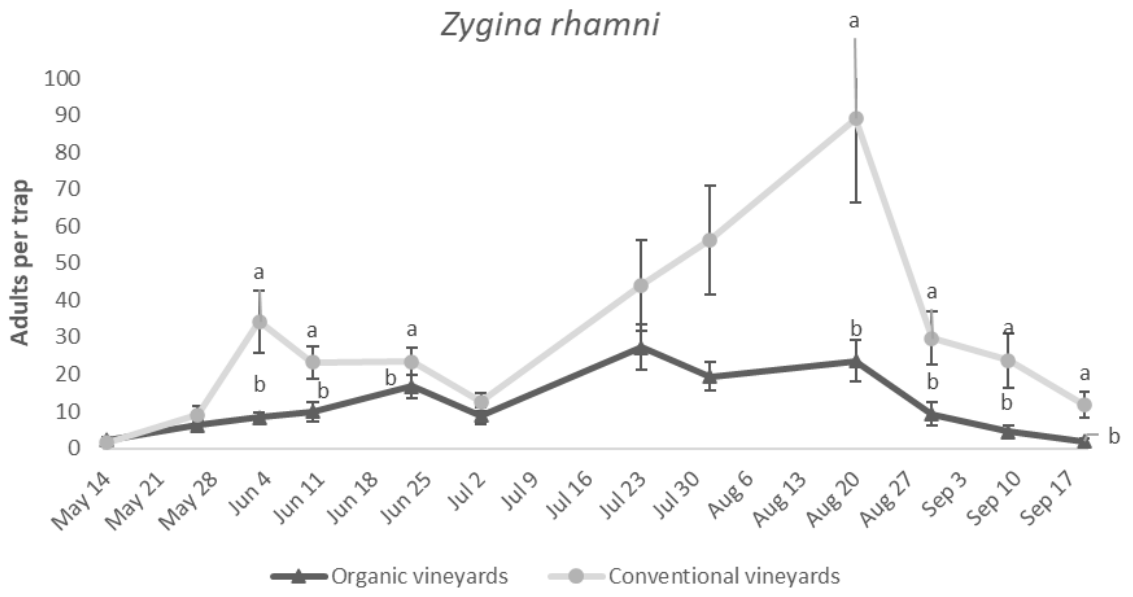

Figure 11. Mean ( \pm std. err.) number of adult E. vulnerata, Z. rhamni and E. vitis catches on traps placed in organic and conventional vineyards. Different letters indicate significant differences based on Tukey's test on least square means $(\alpha=0.05)$ of the number of adults caught on each date.

Erasmoneura vulnerata nymph densities were higher in organic vineyards than in conventional vineyards $(\mathrm{F}=4.61$; d.f. $=1 ; 18 ; p=0.046$; Figure 12). The effect of time was also significant $(\mathrm{F}=3.72$; d.f. $=10,95.1 ; p<0.001 ;$ Figure 11) in contrast to that of the interaction vineyard management ${ }^{*}$ time $(\mathrm{F}=1.43 ;$ d.f. $=10,95.1 ; p=0.18)$. Vineyard management did not affect $E$. vitis or $Z$. rhamni nymphs $(\mathrm{F}=0.66$; d.f. $=1,2.87 ; p=0.478 ; \mathrm{F}=1.8$; d.f. $=1,12.7 ; p=0.203$; for E. vitis and Z. rhamni, respectively, Figure 11). The effect of time and the interaction vineyard management * time were not significant 
for E. vitis $(\mathrm{F}=0.98 ;$ d.f. $=14,60.4 ; p=0.485 ; \mathrm{F}=1.46 ;$ d.f. $=11,57.7 ; p=0.171)$ or Z. rhamni $(\mathrm{F}=1.78$; d.f. $=14,72.4 ; p=0.058 ; \mathrm{F}=1.33 ;$ d.f. $=11,72 ; p=0.227$ ).

\section{Erasmoneura vulnerata}

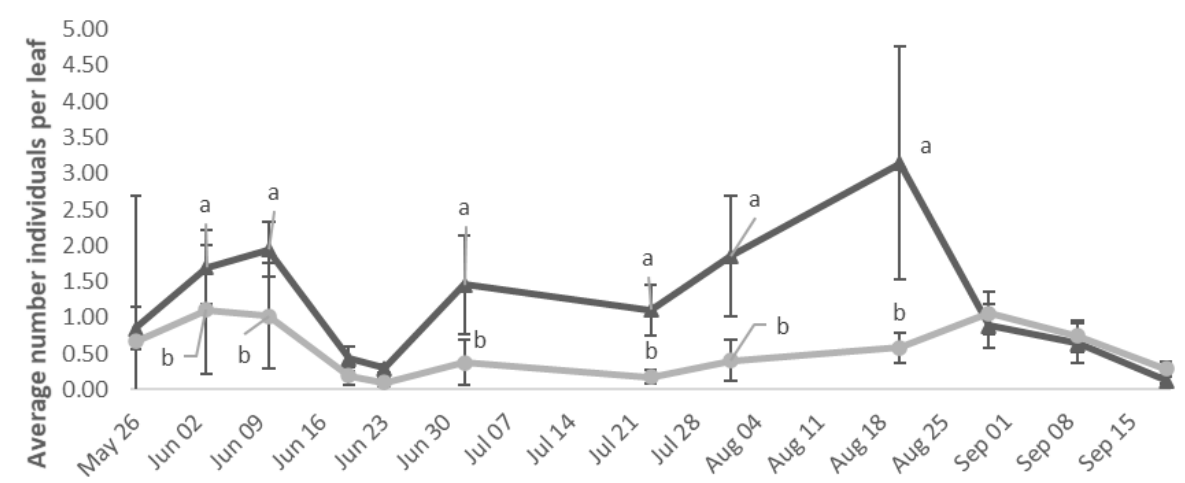

Empoasca vitis

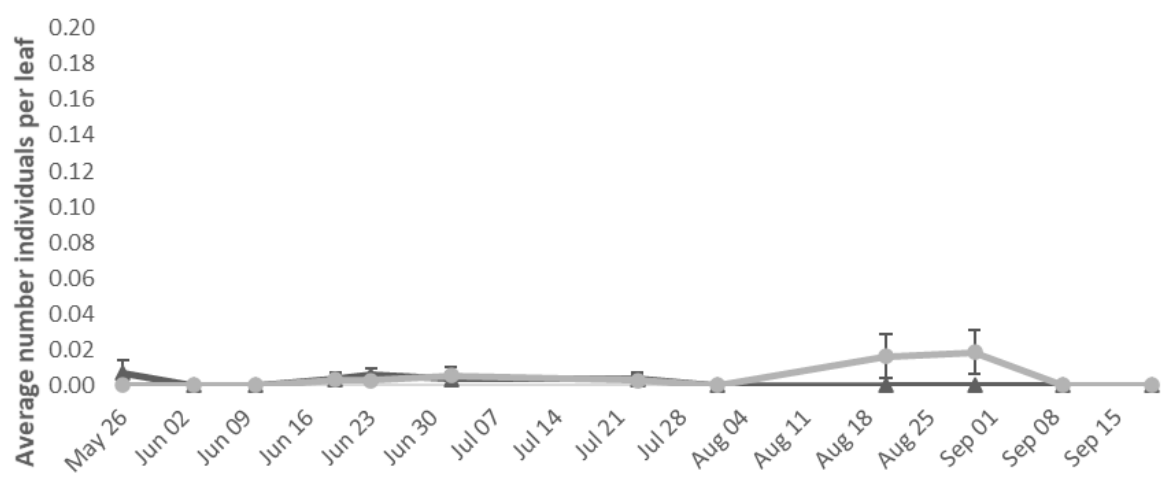

Zygina rhamni

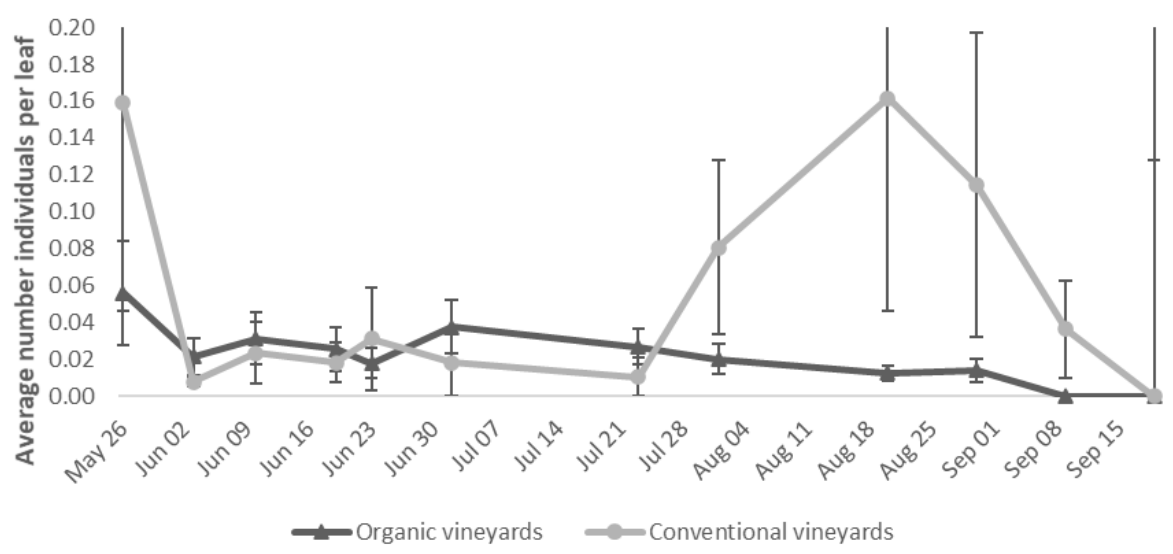

Figure 12. Mean ( \pm std. err.) number of E. vulnerata, E. vitis and Z. rhamni nymphs observed on leaves collected in organic and conventional vineyards. Different letters indicate significant differences at Tukey's test on least square means $(\alpha=0.05)$ of the number of nymphs observed on each date.

Higher parasitism rates from Mymarids were found in organic vineyards (mean $42 \%$ ) compared to conventional vineyards (mean $23 \%)(\mathrm{F}=7.08$; d.f. $=1 ; 19.8 ; p=0.015)$. In organic vineyards, the highest parasitism rates were observed in late spring (55.5\%) and late summer $(54 \%)$. The effect of time was significant $(\mathrm{F}=2.57$; d.f. $=7,66.1 ; p=0.021)$, while the interaction vineyard management ${ }^{*}$ time was not $(\mathrm{F}=1.13$; d.f. $=7,66.1 ; p=0.358)$. This is likely due to the decline in parasitism rates during mid-summer in both situations. 


\section{Discussion}

In their review, Olivier et al. [28] considered E. vulnerata to be among the most economically significant leafhoppers occurring in North American vineyards, something that Zimmerman et al. [13], had already reported 16 years ago. In the latter study, which was conducted in Colorado, E. vulnerata populations were found to be mixed with that of Erythroneura ziczac Walsh, E. ziczac being more frequent. Leafhopper (E. ziczac in particular) abundance implied the need for insecticide applications to reduce possible damage, likely leading to an effect on population densities. Based on observations made in two subsequent years, authors suggested that, in Colorado, E. vulnerata was able to complete two generations per year. To explain why E. vulnerata was less abundant than E. ziczac in these vineyards, Zimmerman et al. [13] suggested three factors: Colorado's environmental conditions, the susceptibility of grape cultivars/hybrids, and the behavior of E. vulnerata nymphs that colonize upper leaf surfaces which, in turn, leads to increased exposure to natural enemies. Years later, Triapitsyn et al. [29] surveyed the same Colorado sites previously investigated by Zimmerman et al. [13] to shed some light on the communities of egg parasitoids associated with grapevine leafhoppers. Surprisingly, E. vulnerata was found to be the dominant species among leafhoppers, while E. ziczac was not detected. These contradictory findings suggest that the pest status of E. vulnerata in native areas is not defined.

Our results highlight the most recent pest status of E. vulnerata in northern Italy. These findings can have serious implications for other Italian regions and European countries (e.g., Switzerland, Slovenia and Serbia) where this pest has been detected more recently. Prior to this study, the damage potential of E. vulnerata was a matter of discussion in North America $[13,29]$ and was just hypothesized about on American grapevine cultivars in Europe [17]. Recent reports of E. vulnerata outbreaks in commercial $V$. vinifera vineyards in southern Europe suggest a need for investigating factors influencing its potential as a new pest. Previous observations on the pest's phenology carried out on Vitis labrusca in Italy suggested that this species could complete two or three generations per year [17]. The present study strongly supports that E. vulnerata completes three generations per year in $V$. vinifera vineyards. In the present study, several V. vinifera cultivars (e.g., Cabernet Sauvignon, Merlot, Chardonnay, Pinot gris, Garganega, Trebbiano, Glera) were found to be equally infested, providing no evidence for variable susceptibility among cultivars located on the same farm. Overwintering is a crucial phase for the success of vineyard colonization by E. vulnerata. Zimmerman et al. [13] detected overwintering adults near the vineyard margins within the evergreen canopy, inside plant structures, or under organic litter. Initial observations carried out in Northern Italy highlighted the importance of rural buildings or hedgerows near vineyards for overwintering and pest colonization [17]. In the present study, a significant edge effect was found in vineyard colonization by E. vulnerata during the spring. In this phase, vineyards were also colonized by the native leafhoppers E. vitis and Z. rhamni, but their incidence in investigated vineyards was very low. Data suggest the possible role of interspecific competition and the need to investigate this phenomenon in controlled conditions. In a vineyard near those investigated in the present study, high numbers of adult E. vulnerata at bud break seriously impacted shoot growth, resulting in the need for control measures.

Among other factors promoting the pest status of E. vulnerata in Northern Italy, tolerance to some pesticides has been suggested [19]. In this study, we investigated the effect of vineyard management on the seasonal abundance of E. vulnerata and found higher pest population densities in organic vineyards. In Italy and in other European countries, organic vineyards can be managed with copper-based fungicides, sulfur, and a few natural insecticides, mostly pyrethrins. Results strongly suggest that these insecticides are less effective than conventional insecticides in keeping leafhoppers at acceptable density levels. Interestingly, predation and parasitism did not increase significantly in organic vineyards to compensate for the low efficacy of pyrethrins or other natural insecticides. Natural control of E. vulnerata and E. ziczac by egg parasitoids in Colorado appeared to be negligible (parasitism rate < $2 \%$ ) [13], while the role of egg parasitoids in newly invaded areas appeared to be promising. The most common egg parasitoid encountered in the present study, A. parvus, is frequently associated with Z. rhamni in north-eastern Italy [20,30]. 
Our results have implications for E. vulnerata control. Knowledge of the "edge effect" in adult colonization could help growers in early detection of this pest and lead to the adoption of adequate control measures. This is particularly important when high leafhopper numbers infest plants at bud break, imposing a threat on shoot growth. In this regard, based on the information provided in the present study, yellow sticky traps should be placed at the vineyard margins in March. This will provide useful information on adult colonization patterns. Data obtained on natural control by Mymarids suggest properly managing areas surrounding vineyards to preserve alternative hosts that promote Mymarid overwintering [31]. Finally, the limited efficacy of pyrethrins against E. vulnerata and their negative side effects on beneficials suggest the need for alternative control measures. Trials have been carried out with kaolin based on the results obtained from other leafhopper species [32]. These trials are showing promising results.

\section{Conclusions}

In conclusion, E. vulnerata completes three generations per year in $V$. vinifera vineyards in Northern Italy. Also, there is no apparent difference in susceptibility among the most common cultivars tested in this study. Our study strongly supports an edge effect on E. vulnerata vineyard colonization during the spring. This aspect should be considered during the application of modern IPM strategies. Also, future investigations should aim to identify control solutions in organic farms where natural insecticides are not very effective. Moreover, the economic impact of $E$. vulnerata on grapevine yield and quality should be investigated to define economic threshold levels and reduce pesticide use.

Author Contributions: Conceptualization, C.D. and A.P.; methodology, C.D., A.P., and G.Z.; formal analysis, C.D., P.T., A.P., and G.Z.; field investigations, P.T., P.G., G.P., D.R., and F.R.; writing-original draft preparation, C.D. and G.Z.; writing-review and editing, P.T. and A.P. All authors have given approval to the final version of the manuscript.

Funding: This work was partially supported by the projects "VIT-VIVE-Innovativi modelli di sviluppo, sperimentazione ed applicazione di protocolli di sostenibilità della vitivinicoltura veneta" (POR-FESR Regione Veneto) to C.D. and A.P., BIRD167802/16 to A.P. and DOR (University of Padova) to C.D. and A.P.

Acknowledgments: We thank Dmitry A. Dmitriev (Illinois Natural History Survey) for suggestions, Luca Mazzon and Isabel Martinez-Sanudo (DAFNAE, University of Padova) for the identification of Anagrus parvus, Francesco Pavan (University of Udine) for comments to the manuscript, Aldo Lorenzoni, Giuseppe Rama e Mirko Trevisi for assistance in the farm selection, Logan Moore for revising the final version of the manuscript. Finally, we thank two anonymous reviewers for improving substantially the manuscript.

Conflicts of Interest: The authors declare no conflict of interest.

\section{References}

1. McAtee, W.L. Key to the nearctic species and varieties of Erythroneura (Homoptera; Eupterygidae). Trans. Am. Entomol. Soc. 1920, 46, 267-321.

2. Johnson, D.M. Leafhoppers of Ohio. Subfamily Typhlocybinae (Homoptera: Cicadellidae). Bull. Ohio Biol. Surv. 1935, 6, 39-122.

3. Metcalf, Z.P. General Catalogue of the Homoptera. VI. Cicadelloidea. Part 17; United States Department of Agriculture, Agricultural Research Service: Washington, DC, USA, 1968; Volume 6, p. 1513.

4. Dmitriev, D.A.; Dietrich, C.H. Review of the New World Erythroneurini (Hemiptera: Cicadellidae: Typhlocybinae). I. Genera Erythroneura, Erasmoneura, Rossmoneura, and Hymetta. Ill. Nat. Hist. Surv. 2007, 38, 59-128.

5. Wilson, L.T.; Barnes, M.M.; Flaherty, D.L.; Andris, H.L.; Leavitt, G.M. Variegated Grape Leafhopper. In Grape Pest Management; University of California, Division of Agriculture and Natural Resources: Oakland, CA, USA, 1992; Volume 3343, pp. 202-213.

6. Daane, K.M.; Yokota, G.Y.; Zheng, Y.; Hagen, K.S. Inundative release of common green lacewings (Neuroptera: Chrysopidae) to suppress Erythroneura variabilis and E. elegantula. (Homoptera: Cicadellidae) in vineyards. Environ. Entomol. 1996, 25, 1224-1234. [CrossRef] 
7. Costello, M.J. Regulated deficit irrigation and density of Erythroneura spp. (Hemiptera: Cicadellidae) on grape. J. Econ. Entomol. 2008, 101, 1287-1294. [PubMed]

8. Dmitriev, D.A. 3I Interactive Keys and Taxonomic Databases. Auchenorrhyncha Database Search. Available online: http://dmitriev.speciesfile.org (accessed on 19 November 2018).

9. Robinson, W. The genus Erythroneura north of Mexico (Homoptera, Cicadellidae). Sci. Bull. Univ. Kans. 1926, 16, 101-155. [CrossRef]

10. Beamer, R.H. The Erythroneura of the vulnerata group (Homoptera-Cicadellidae). J. Kans. Entomol. Soc. 1946, 19, 15-22.

11. Martinson, T.E.; Dennehy, T.J. Varietal preferences of Erythroneura leafhoppers (Homoptera: Cicadellidae) feeding on grapes in New York. Environ. Entomol. 1995, 24, 550-558. [CrossRef]

12. Paxton, D.W.; Thorvilson, H.G. Oviposition of three Erythroneura species on grape leaves in Western Texas. Southwest. Entomol. 1996, 21, 141-144.

13. Zimmerman, R.; Kondratieff, B.; Nelson, E.; Sclar, C. The life history of two species of grape leafhoppers on wine grapes in western Colorado. J. Kans. Entomol. Soc. 1996, 69, 337-345.

14. Duso, C.; Bressan, A.; Mazzon, L.; Girolami, V. First record of the grape leafhopper Erythroneura vulnerata Fitch (Hom., Cicadellidae) in Europe. J. Appl. Entomol. 2005, 129, 170-172. [CrossRef]

15. Girolami, V.; Duso, C.; Mazzon, L.; Bressan, A. Nuova cicalina della vite in Italia. Inf. Agric. 2006, 62, 65-67.

16. Duso, C.; Moret, R.; Marchegiani, G.; Pozzebon, A. Notes on the distribution and the phenology of Erasmoneura vulnerata (Fitch) (Homoptera: Cicadellidae) in North-eastern Italy. IOBC/WPRS Bull. 2008, 36, 251-254.

17. Duso, C.; Moret, R.; Manera, A.; Berto, D.; Fornasiero, D.; Marchegiani, G.; Pozzebon, A. Investigations on the grape leafhopper Erasmoneura vulnerata in North-eastern Italy. Insects 2019, 10, 44. [CrossRef] [PubMed]

18. Seljak, G. First record of the Nearctic leafhopper Erasmoneura vulnerata (Fitch, 1851) (Hemiptera, Cicadomorpha: Cicadellidae) in Slovenia. Acta Entomol. Slov. 2011, 19, 37-42.

19. Duso, C.; Borgo, M.; Pozzebon, A.; Mazzon, L.; Mori, N.; Pavan, F.; Fornasiero, D.; Marchesini, E.; Martinez-Sañudo, I.; Zanettin, G. Vite: Erasmoneura vulnerata, una minaccia da valutare. Inf. Agric. 2017, 44, 31-35.

20. Rizzoli, A.; Battelli, R.; Conedera, M.; Jermini, M. First record of Erasmoneura vulnerata Fitch, 1851 (Hemiptera, Cicadellidae, Typhlocybinae) in Switzerland. Alp. Entomol. 2020, 4, 151.

21. Šćiban, M.; Kosovac, A. New records and updates on alien Auchenorrhyncha species in Serbia. Pesticidi $i$ Fitomedicina 2020, 35, 9-16.

22. Zanolli, P.; Pavan, F. Autumnal emergence of Anagrus wasps, egg parasitoids of Empoasca vitis, from grapevine leaves and their migration towards brambles. Agric. For. Entomol. 2011, 13, 423-433. [CrossRef]

23. Vidano, C. Le cicaline italiane della vite. Hemiptera Typhlocibinae. Boll. Zool. Agr. Bachic. 1958, 1, 61-115.

24. Patwary, M.U.; Kenchington, E.L.; Bird, C.J.; Zouros, E. The use of random amplified polymorphic DNA markers in genetic studies of the sea scallop Placopecten magellanicus (Gmelin, 1791). J. Shellfish Res. 1994, 13, 547-553.

25. Martinez-Sañudo, I.; Mazzon, L.; Simonato, M.; Avtzis, D.; Pujade-Villar, J.; Faccoli, M. Tracking the origin and dispersal of the Asian chestnut gall wasp Dryocosmus kuriphilus Yasumatsu (Hymenoptera, Cynipidae) in Europe with molecular markers. Bull. Entomol. Res. 2019, 109, 300-308. [CrossRef] [PubMed]

26. Viggiani, G. On the misidentification of Anagrus ustulatus Haliday (Hymenoptera: Mymaridae). Zootaxa 2014, 3826, 397-400. [CrossRef] [PubMed]

27. Mazzon, L.; Martinez-Sañudo, I. (DAFNAE University of Padova, Legnaro, Italy). Personal communication, 2019.

28. Olivier, C.; Vincent, C.; Saguez, J.; Galka, B.; Weintraub, P.G.; Maixner, M. Leafhoppers and planthoppers: Their bionomics, pathogen transmission and management in vineyards. In Arthropod Management in Vineyards; Springer: Dordrecht, The Netherlands, 2012; pp. 253-270.

29. Triapitsyn, S.V.; Rugman-Jones, P.F.; Jeong, G.; Morse, J.G.; Stouthamer, R. Morphological and molecular differentiation of the Anagrus epos species complex (Hymenoptera: Mymaridae), egg parasitoids of leafhoppers (Hemiptera: Cicadellidae) in North America. Zootaxa 2010, 2428, 1-21. [CrossRef]

30. Zanolli, P.; Martini, M.; Mazzon, L.; Pavan, F. Morphological and Molecular identification of Anagrus 'atomus' Group (Hymenoptera: Mymaridae) individuals from different geographic areas and plant hosts in Europe. J. Insect Sci. 2016, 16, 38. [CrossRef] 
31. Ponti, L.; Ricci, C.; Veronesi, F.; Torricelli, R. Natural hedges as an element of functional biodiversity in agroecosystems: The case of a Central Italy vineyard. Bull. Insectol. 2005, 58, 19-23.

32. Tacoli, F.; Pavan, F.; Cargnus, E.; Tilatti, E.; Pozzebon, A.; Zandigiacomo, P. Efficacy and mode of action of kaolin in the control of Empoasca vitis and Zygina rhamni (Hemiptera: Cicadellidae) in vineyards. J. Econ. Entomol. 2017, 110, 1164-1178. [CrossRef]

Publisher's Note: MDPI stays neutral with regard to jurisdictional claims in published maps and institutional affiliations.

(C) 2020 by the authors. Licensee MDPI, Basel, Switzerland. This article is an open access article distributed under the terms and conditions of the Creative Commons Attribution (CC BY) license (http://creativecommons.org/licenses/by/4.0/). 